УДК 81'42:32

ББК 81.432.1

DOI: https://doi.org/10.17308/lic.2020.1/2737

\title{
ПРАГМАЛИНГВИСТИЧЕСКИЕ СРЕДСТВА КОНСТРУИРОВАНИЯ КОЛЛЕКТИВНОГО ПРОШЛОГО В БРИТАНСКОМ ПОЛИТИЧЕСКОМ ВЫСТУПЛЕНИИ
}

\author{
Т. В. Дубровская, Э. И. Юськаева \\ Пензенский государственный университет
}

\author{
PRAGMALINGUISTIC MEANS OF CONSTRUCTING \\ THE COMMON PAST IN BRITISH POLITICAL SPEECH
}

\author{
T. V. Dubrovskaya, E. I. Yuskaeva \\ Penza State University
}

\begin{abstract}
Аннотация: статья является частью исследования, направленного на изучение способов дискурсивного конструирования британской национальной идентичности. В настоящей статье мы ставим задачу выявить прагмалингвистические средства конструирования коллективного прошлого как компонента идентичности в британском Брексит-дискурсе. В качестве материала использованы тексть выступлений британских политиков, доступные для скачивания на официальных сайтах кампаний «Vote Leave» $u$ «Britain Stronger in Europe». Задача исследования решается посредством методик критического дискурс-анализа. В результате выделены две ключевые стратегии конструирования коллективного прошлого: стратегия объединения государств и стратегия дистанцирования государств. Установлены различия в конструировании коллективного прошлого противниками и сторонниками Брексита. Если в выступлениях противников конструируется общее с Европой прошлое, то в выступлениях сторонников под коллективным прошлым подразумевается общее прошлое британской начии. Спектр прагмалингвистических средств, используемых в рамках указанных стратегий, включает отсылки к значимым событиям и датам истории, лексику с темпоральной семантикой и семантикой единения, грамматические маркеры прошлого, метафоры и идиомы, инклюзивные именные сочетания, лексические маркеры положительной и отрицательной оченки. Перспективы исследования представляются в расширении материала и диахроническом изучении средств конструирования идентичности в британском политическом дискурсе.

Ключевые слова: нащиональная идентичность, Брексит, коллективное прошлое, тематический блок, стратегия, языковые средства.
\end{abstract}

\begin{abstract}
British national identity. This article aims to reveal what pragmalinguistic tools are used to construct the common past as a component of the identity in British Brexit-discourse. The data include speeches by British politicians retrieved from the official websites of the campaigns "Vote Leave" and "Britain Stronger in Europe". In terms of methodology, the study draws on techniques of critical discourse analysis. As a result, two key strategies of constructing the common past are identified. These strategies include the strategy of grouping countries and the strategy of distancing countries. The common past is constructed along different lines the Remainers and the Brexiteers. In the speeches by the Remainers the common past is constructed as shared with Europe, whereas in the Brexiteers' speeches it is constructed as belonging to the British nation only. The range of pragmalinguistic resources used within these strategies includes references to significant historic events and dates, lexemes with temporal semantics and the semantics of unity, grammatical markers of the past, metaphors and idioms, inclusive noun phrases, lexical markers of positive and negative evaluation. The prospects for research include the expansion of the data and the diachronic study of the discursive construction of identity in the British political discourse.
\end{abstract}

Key words: national identity, Brexit, common past, thematic area, strategy, linguistic means.

(С Дубровская Т. В., Юськаева Э. И., 2020

Контент доступен под лицензией Creative Commons Attribution 4.0 License.

The content is available under Creative Commons Attribution 4.0 License. 
В настоящее время актуальны проблемы, связанные с определением, поиском и отстаиванием национальной идентичности. Исследования, посвященные изучению национальной идентичности, появляются как в отечественной, так и в зарубежной лингвистике [1-3]. В данной статье мы исследуем языковые и шире - прагмалингвистические - средства конструирования такого аспекта национальной идентичности, как коллективное прошлое, в британском политическом дискурсе в контексте Брексита.

Исследование британского дискурса о Брексите происходит в различных направлениях. Актуальным направлением является лингвокогнитивный анализ концептуальных метафор в британском медиадискурсе в период Брексита [4; 5]. В фокусе исследования Е. Ю. Дьяковой находится использование социально-политического феномена Брексит в целях создания позитивного имиджа британского университета [6]. Т. В. Алиева исследует оппозицию «свой-чужой» и языковые средства ее актуализации в британской прессе в период Брексита [7].

Новизна предлагаемого подхода к Брексит-дискурсу состоит в том, что политический дискурс современности исследуется в тесной связи с дискурсивными проявлениями национальной идентичности. Обращение к темпоральным аспектам национальной идентичности позволяет установить, как политические установки актуализируются с опорой на интерпретации событий прошлого, настоящего и будущего. В данной статье рассматривается аспект коллективного прошлого.

Прежде чем обратиться к речевому материалу, определим базовые исследовательские категории, такие как национальная идентичность, коллективное прошлое, дискурсивное конструирование и прагмалингвистические средства.

Рассмотрение национальной идентичности целесообразно начинать с обращения к более общей категории идентичности. Авторы словаря ключевых терминов дискурс-анализа П. Бейкер и С. Эллес отмечают, что «идентичность»- относительно новая категория в социальных исследованиях, а два различных подхода к идентичности определяют ее либо как внутренне обусловленную, устойчивую сущность, либо как «осознанное внутреннее принятие социально обязывающих или социально конструируемых ролей» [8, р. 58] (Перевод с английского здесь и далее наш. - Т. Д., Э. Ю.). Мы придерживаемся конструкционистских позиций, принятых за философскую основу критического дискурс-анализа, и показываем, что идентичность представляет собой гибкий социальный конструкт, создаваемый в процессе коммуникации. «Национальные идентичности <..> дискурсивно, т. е. посредством языка и других семиотических систем, производятся, вос- производятся, трансформируются и разрушаются» [9, p. 153].

Важно, что идентичность отвечает не только на вопрос «Кто мы?», но и на вопрос «Кто мы по отношению друг к другу?» [10, p. 6]. К. С. Гаджиев отмечает, что «согласно закону противоречия и по аналогии с противопоставлением “мы-они”, “свои-чужие”, “друг-враг”, идентичность обязательно должна быть подкреплена образом противника, внешнего врага, который служит мощным стимулятором достижения консолидации и эффективности человеческих сообществ» $[11$, с. 8]. Подобного мнения о конструировании идентичности в терминах оппозиции придерживаются и зарубежные исследователи, полагая, что идентичность «дает нам представление о том, кто мы и как соотносимся с другими людьми и с миром, в котором живем. Идентичность отмечает, в чем мы похожи с теми, кто разделяет наше положение, и чем мы отличаемся от тех, кто его не разделяет» [12, p. 1-2]. Представляется, что именно отношения противопоставления определяют характер конструирования (в том числе дискурсивного) национальной идентичности.

На сегодняшний день нет единого мнения относительно структуры национальной идентичности. Так, К. С. Гаджиев выделяет следующие ее компоненты: «мировоззрение, национальное самосознание и менталитет, национальный характер, историческая память, этнонациональные образы, национальные традиции, мифы, символы, стереотипы и др.» [11, c. 5]. К. Линч отмечает, что все материальные объекты (церкви, здания, окрестности, памятники, парки, улицы) служат пространственными координатами идентичности [13, p. 150].

Поскольку, как было отмечено выше, идентичность конструируется в значительной мере в процессе коммуникации, язык и национальная идентичность образуют неразрывную связь.

Ранее в одной из своих работ мы представили обзор факторов, определяющих взаимосвязь идентичности и языка, подчеркивая при этом, что «владение языком необходимо не только с коммуникативной целью. Важна и его этноконсолидирующая функция» [1, с. 27]. Мы также на речевом материале продемонстрировали, что сформированная национальная идентичность индивида может успешно выражаться как на родном, так и на неродном языке. Для анализа дискурсивных проявлений национальной идентичности была предложена модель анализа, охватывающая три уровня: содержательный, коммуникативный и металингвистический [1] .

Иная модель анализа национальной идентичности через дискурс предложена в работе Е. А. Кожемякина, который выделяет конкретные дискурсивные узлы, характерные для нее: 1) номинации, фиксиру- 
ющие семиотический статус национальной принадлежности; 2) исторический нарратив (категории прошлого, настоящего и будущего выступают в качестве конструирующих эпистемических ресурсов); 3) использование категорий «мы-они» («свои-чужие»); 4) образы культуры и территории; 5) обращение к социально-политическим аспектам [14, с. 27]. Обратим внимание на выделение категорий прошлого, настоящего и будущего.

Темпоральные смысловые категории прошлого, настоящего и будущего отмечены и в работе Р. Водак [3, p. 30-31]. Таким образом, коллективное прошлое составляет часть национальной идентичности.

Механизм функционирования коллективной памяти описывает О. А. Солопова: «коллективная память воздействует на жизнь двумя путями: 1) дает модель общества как отражение потребностей, проблем, страхов, менталитета и ожиданий и 2) предлагает модель общества как программу, определяет общественный опыт, артикулирует ценности, цели, когнитивные, аффективные и моральные ориентиры для реализации данной программы» [15, с. 19]. Таким образом, прошлое не просто неразрывно связано с настоящим, а выступает некоторой его формой. Исследовательница отмечает, что «в рамках некоторой официальной ревизии настоящего, а вместе с ним и прошлого происходит переструктурирование политических смыслов - реинтерпретация настоящего» [Там же, с. 24].

Таким образом, под коллективным прошлым мы понимаем дискурсивно конструируемую смысловую категорию, которая представляет собой один из блоков национальной идентичности и актуализируется посредством дискурсивных стратегий. За основу понимания стратегии мы берем определение, предложенное в работах западных дискурс-аналитиков, в соответствии с которым стратегия - это «более или менее намеренный план практических действий (включая дискурсивные действия), принятый для достижения конкретной социальной, политической, психологической или лингвистической цели» [16, p. 94].

Поскольку стратегия является категорией прагматической и когнитивной, а не собственно лингвистической, и реализуется посредством применения конкретных средств разных уровней языка, далее в анализе мы пишем о прагмалингвистических средствах конструирования коллективного прошлого.

Целью настоящей статьи является выявление спектра прагмалингвистических средств, используемых при конструировании коллективного прошлого как одного из компонентов британской национальной идентичности в британском политическом выступлении.

Материалом исследования послужили публичные выступления британских политических деятелей в период до и после проведения референдума о членстве Великобритании в Европейском союзе (20132018 гг.). В ходе двух организованных кампаний «Vote Leave» и «Britain Stronger in Europe» политики выразили противоположные мнения по вопросу выхода Великобритании из Европейского союза. При этом для аргументации своей позиции они нередко обращались к коллективному прошлому. В качестве источника материалов были использованы официальные сайты кампаний «Vote Leave» (www.voteleavetakecontrol.org) и «Britain Stronger in Europe» (www. strongerin.co.uk), официальный сайт правительства Великобритании (https:/www.gov.uk/), официальные сайты газет (https://www.newsweek.com/, https://www. spectator.co.uk/) и некоторые другие интернет-ресурсы. Общее количество проанализированного материала - 20 выступлений. Список процитированных в статье выступлений приведен в списке источников.

В качестве исследовательской методики нами была применена трехступенчатая модель анализа идентичности, предложенная Р. Водак [3]. Австрийская исследовательница предлагает осуществлять анализ материала с точки зрения: содержания (contents); стратегий аргументации (strategies); средств и форм лингвистической реализации (means and forms of realisation) [3, p. 30].

Процедурный алгоритм нашего исследования можно описать следующим образом.

1. Содержание. На первом этапе материал исследуется на содержательном уровне. Выделяются смысловые фрагменты, в которых присутствует эксплицитное указание на прошлое отдельно сторонниками и противниками Брексита. Формируется тематический блок «Коллективное прошлое».

2. Дискурсивные стратегии. В обнаруженных фрагментах, объединенных репрезентацией коллективного прошлого, выделяются характерные для данного блока стратегии. При этом особое внимание уделяется тому, как репрезентируются отношения между различными социальными акторами коллективного прошлого. На данном этапе выделяются общие и различные для сторонников и противников Брексита стратегии.

3. Языковые средства. В рамках выделенных дискурсивных стратегий определяются и систематизируются конкретные языковые средства создания и интерпретации коллективного прошлого.

Поскольку исследование репрезентаций коллективного прошлого предполагает внимание к дискурсивному конструированию групп (коллективов), мы применяем также ранее апробированную методику А. Совиньской и Т. Дубровской [17]. По данной методике выделяются две группы языковых средств: 1) используемые для конструирования групп и определения отношений между членами группы; 2) ис- 
пользуемые для установления межгрупповых отношений. Каждая из этих групп имеет специфический набор. Первая группа включает лексику с семантикой единения, повторяющиеся синтаксические конструкции со значением единения, лексические маркеры положительных эмоций, относящиеся к членам группы. Межгрупповые отношения маркируются ссылками на отрицательные эмоции, вызываемые другой группой, а также эксплицитными или имплицитными указаниями на угрозу со стороны группы «иных» [17, р. 453-454]. Таким образом, систематизация языковых средств с опорой на данную методику позволит определить стратегическую направленность предлагаемых в политических выступлениях интерпретаций наицональной идентичности.

С точки зрения содержания, тематический блок «Коллективное прошлое» образован фрагментами выступлений, содержащих ссылки на значимые события прошлого, важные даты и имена.

В рамках этого тематического блока были выделены две ключевые стратегии конструирования коллективного прошлого: стратегия объединения государств и стратегия дистанцирования государств. Каждая из этих стратегий последовательно реализуется политическими деятелями, представляющими разные политические взгляды в контексте Брексита: стратегия объединения государств - противниками выхода из EC, а стратегия дистанцирования государств - сторонниками Брексита.

\section{Стратегия объединения государств}

Стратегия объединения государств состоит в том, чтобы обозначить необходимость единения Британии с другими государствами в рамках Европейского союза. Данная стратегия используется в контексте обсуждения событий прошлого противниками Брексита. Коллективное прошлое Великобритании и других европейских государств представлено репрезентациями ключевых событий, занимающих важное место в коллективной памяти. События прошлого «перерабатываются» политиками и представляются в выгодном для репрезентации идентичности ключе. Обращение к уязвимым областям коллективной памяти происходит с целью акцентировать неразрывную связь Великобритании и Европы, которая подкрепляется общей историей, и сохранить членство Великобритании в ЕC.

Общее европейское прошлое, частью которого представлена Британия, касается прежде всего участия европейских стран в мировых войнах. Апеллируя к этим событиям, противники Брексита создают мрачный образ военного прошлого.

(1) Seventy years ago, Europe was being torn apart by its second catastrophic conflict in a generation. A war which saw the streets of European cities strewn with rubble. The skies of London lit by flames night after night. And millions dead across the world in the battle for peace and liberty.

And it is the inscriptions on their gravestones - their names, their ages, the unknown soldiers - that to this day call upon us, the post war generation, to do everything within our grasp to stop that slaughter from happening again (Benn 13.06.2016).

Метафоры (lit by flames, cities strewn with rubble, healing the wounds of history, was being torn apart) использованы для отрицательно-оценочных репрезентаций Второй мировой войны, называемой кровопролитием, катастрофой: slaughter, catastrophic conflict. Важно, что в примере (1) Лондон представлен как один из европейских городов, пострадавших от войны.

История Европы и история Великобритании показаны как неразрывно связанные:

(2) For good or ill, we have written Europe's history just as Europe has helped to write ours (Cameron 9.05.16).

Детальное обращение к образу войны может рассматриваться не только с точки зрения анализа уроков прошлого, но и как предупреждение о новых угрозах в будущем, перед лицом которых следует объединиться. Для противников Брексита безопасность и мир могут быть гарантированы лишь при условии членства в Европейском союзе:

(3) This vision was the most eloquent and enduring memorial we could have built to the flower of two generations of young Europeans who gave their lives in war and now rest eternal in those immaculately cared-for cemeteries (Benn 13.06.2016).

Для высказываний характерно грамматическое указание на прошлое посредством перфектных инфинитивов и времени Past Simple (could have built, gave their lives). Лексика с темпоральной семантикой (memorial, generations, eternal) выступает индикатором исторических и межпоколенческих связей. Сказуемое в настоящем простом времени Present Simple (rest eternal) подчеркивает связь прошлого и настоящего поколений. Номинация участников войны как «европейцев» или «неизвестных солдат», без указания на их национальную принадлежность актуализирует единение с Европой. Кроме того, отметим использование инклюзивного местоимения we, которое в данном контексте можно истолковать как средство конструирования группы «Британия + Европа».

Как следует из содержания выступлений, именно единство Европейского союза помогло преодолеть страшные последствия мировых войн, а также гарантировать мир и безопасность.

Общеевропейское культурное прошлое также используется британскими политиками как аргумент 
в пользу единения с Европой. Примечательно, что в ряде выступлений обнаруживается связь тематики с выбранной локацией или определенной датой. Нахождение в конкретном месте в момент выступления позволяет использовать этот факт для актуализации в речи своих стратегических установок. Так, выступление Т. Мэй, занимающей пост министра внутренних дел на период проведения референдума и поддерживающей на тот момент политику Remain, происходит во Флоренции, городе, известном произведениями искусства и архитектурой эпохи Возрождения и символизирующем новый этап в отношениях с Европой:

(4) It's good to be here in this great city of Florence today at a critical time in the evolution of the relationship between the United Kingdom and the European Union. $<\ldots>$ It was here, more than anywhere else, that the Renaissance began - a period of history that inspired centuries of creativity and critical thought across our continent and which in many ways defined what it meant to be European (May 22.09.2017).

Ссылка на Ренессанс, берущий начало в итальянской Флоренции, развивается в виде суждения о целых веках общей истории, творчества и критической мысли. При этом единение с Европой актуализируется инклюзивным именным словосочетанием our continent (наш континент) и упоминанием общеевропейской идентичности (what it meant to be European).

Важное место в коллективной памяти противников отделения от Европы занимает само основание Евросоюза. Создание Европейского союза рассматривается противниками Брексита как необходимая мера для обеспечения безопасности на континенте:

(5) Arising from the ashes of the Second World War, the nations of the world came together $<\ldots>$ The roots of the European Union also took hold in those same ashes and drew upon those same principles.

And by the creation of the European Coal and Steel Community - bringing former foes together-its founders resolved to make a return to conflict on the continent of Europe - in the words of the Schuman Declaration - "not merely unthinkable, but materially impossible” (Benn 13.06.2016).

Апелляция к историческому факту объединения бывших врагов (bringing formerfoes together) подчеркивает факт преодоления последствий войны. Символично использование в данном примере аллюзии arise from the ashes: «Это выражение содержит аллюзию на легендарного феникса, птицу, которая восстала заново рожденной из пепла своего погребального костра» [18].

Стратегия объединения государств актуализируется в значительной степени за счет высокой частотности в употреблении лексических единиц разной частеречной принадлежности, фразовых глаголов и фразеологизмов с семантикой единения: have been intertwined, global connections, came together, stood shoulder in shoulder, in cooperation, bring together и др.

\section{Стратегия дистанцирования}

В научной литературе отмечено, что дистанцированность является одной из лингвокультурных особенностей британского народа [19]. Личное пространство, свобода действий и независимость представляют особую ценность для британцев. Это отражается на их коммуникативном поведении. Сохранение дистанции дает возможность защитить личное пространство коммуникантов и обеспечить успешность речевого взаимодействия [20]. Вопрос о связи национального менталитета и политической повестки выхода из ЕС, вероятно, требует отдельного рассмотрения. В контексте анализа нашего материала мы исследуем стратегию дистанцирования не как характеристику межличностной коммуникации, а как черту политического дискурса. Стратегия дистанцирования состоит в том, чтобы представить Великобританию как самостоятельное государство со своим собственным коллективным прошлым. Стратегия дистанцирования Британии от Евросоюза используется в выступлениях сторонников Брексита.

Исторический факт создания Евросоюза интерпретируется сторонникам Брексита совсем в ином свете по сравнению с представлением противников выхода из ЕС. Сторонниками Брексита проект Европейского союза воспринимается как попытка создать не просто политическое образование, но и единые общеевропейские сознание и идентичность (Europeanness, a European identity and a European consciousness):

(6) $<\ldots>$ Their inspired idea was to weave a cat's cradle of supranational legislation that would not only bind the former combatants together, but create a new sensation of Europeanness.

As Schuman put it, "Europe will be built through concrete achievements which create a de facto solidarity." Jean Monnet believed that people would become "in mind European", and that this primarily functional and regulatory approach would produce a European identity and a European consciousness.

Almost 60 years after the Treaty of Rome, I do not see many signs that this programme is working (Johnson 14.02.2018).

Логика данного фрагмента построена на том, что говорящий сначала представляет благие намерения создателей Евросоюза объединить бывших врагов (bind the former combatants together) и построить настоящую солидарность (create a de facto solidarity). Однако фрагмент заканчивается утверждением о том, что план не сработал. Таким образом, создается сти- 
листический эффект обманутого ожидания, посредством которого общеевропейское прошлое интерпретируется как ошибка.

Коллективное прошлое сторонников Брексита представлено событиями из истории британской нации. Значимые события коллективной памяти использованы с целью подчеркнуть уникальность и определенное превосходство Великобритании.

Одно из достоинств коллективного прошлого нации состоит, по мнению выступающих, в постоянном стремлении к свободе, демократии и укреплению прав человека. Подписание Великой хартии вольностей в 1215 г., акта Хабеас корпус и права наследования получают репрезентации значимых компонентов коллективной памяти нации:

(7) We have given up our concept of civil rights. Magna Carta, 800th anniversary the year after next, at the general election.

Habeas corpus. Rights of inheritance. And not just for the aristocracy, as time went by (Farage 20.09.2013).

Великое прошлое, ассоциируемое с достижениями в области прав человека, противопоставляется современной ситуации, связанной с отказом от прежних достижений (We have given up our concept of civil rights).

Другое историческое достижение Британии, упоминаемое в контексте Брексита, - это собрание первого выборного Парламента в 1265 г.:

(8) And this right of redress of grievance is something that has existed since Parliament first assembled in 1265. It is one of our most ancient rights but once it's a European competence that ancient right has gone (Mogg 10.06.2016).

В этом примере прошлое также связывается с настоящим - Евросоюз обвиняется в том, что происходит отказ от прежних достижений (once it's a European competence that ancient right has gone). Таким образом, происходит диссоциация современной Британии и Европы.

Одним из событий, определяющих идентичность британской нации, представлена индустриальная революция:

(9) It was also Britain that led the industrial revolution and destroyed slavery and the British people who had the wit to see through the bogus attractions of protectionism and who campaigned for free trade that has been the single biggest engine of prosperity and progress (Johnson 14.02.2018).

В данном отрывке из выступления Б. Джонсона Британия репрезентируется как лидер развития и прогресса в прошлом (led the industrial revolution, destroyed slavery). Спикер выстраивает связь между достойным прошлым с современным состоянием Британии и прозорливыми современниками, способными видеть обман (had the wit to see through the bogus attractions). Прошлое в данном контексте выступает залогом успешного прогрессивного будущего страны (prosperity and progress). С точки зрения языка востребованными оказываются расщепленные предложения (cleft sentences), используемые с эмфатической целью (It was also Britain that... and the British people who...), а также лексические маркеры положительной оценки, использованные для характеристики Британии.

На противопоставлении великого исторического прошлого и современного состояния Британии в составе ЕС построено и следующее высказывание:

(10) It is absurd that Britain - historically a great free-trading nation - has been unable for 42 years to do a free trade deal with Australia, New Zealand, China, India and America (Johnson 09.05. 2016).

Положительная оценка прошлого Британии как великого государства со свободной торговлей (historically a great free-trading nation) комбинируется с признанием абсурдности текущей ситуации (it is absurd), когда Британия не может самостоятельно, без участия EC, вступать в торговые отношения с неевропейскими государствами. Противопоставление Британии Европе получает эксплицитное выражение в речи в виде эпитетов с разной оценочной коннотацией (great - absurd).

Проведенное исследование показало, что коллективное прошлое является дискурсивно конструируемой категорией и частью публичной актуализации британской национальной идентичности. В рамках тематического блока «Коллективное прошлое» используются две основные стратегии: стратегия объединения государств и стратегия дистанцирования государств. В зависимости от целого ряда факторов (политической повестки, стратегических установок политиков, потребностей в легитимации тех или иных политически значимых действий) коллективное прошлое как совокупность ряда фактов получает различные и нередко противоположные интерпретации в политическом дискурсе. Для противников Брексита коллективное прошлое означает общее прошлое Великобритании и Европы, что свидетельствует о продвижении общеевропейской идентичности. Ведущую роль в реализации стратегии объединения играют лексические единицы с семантикой единения, инклюзивные конструкции.

Для сторонников Брексита коллективом является собственная нация, и в их выступлениях коллективное прошлое представлено как прошлое собственного государства, Великобритании. Сторонники Брексита противопоставляют группы «Мы» (Великобритания) и «Они» (Европа), а также подчеркивают собственное национальное превосходство. Кроме того, конструируется оппозиция между великим самостоятельным прошлым Великобритании и неудовлетворительным 
настоящим в составе ЕС. Для актуализации этих оппозиций важны противопоставления, а также лексические маркеры положительной и отрицательной оценки.

Таким образом, репрезентации прошлого позволяют британским политикам конструировать в своем публичном дискурсе такую национальную идентичность, которая соответствует их политической программе.

\section{ЛИТЕРАТУРА}

1. Дубровская T. В. 'I Was the First Westerner, The Only English Person: дискурсивное конструирование национальной идентичности // Вестник Рос. ун-та дружбы народов. Сер. Лингвистика. 2015. № 2. С. 25-40.

2. Кожемякин Е. А., Крюкова С. В. Языковое моделирование национальной идентичности в политическом медиадискурсе (на материале новогодних телеобращений В. В. Путина к Федеральному собранию) // Современный дискурс-анализ. 2018. № 3-2 (20). С. 80-95.

3. Wodak R., Cillia R. de, Reisigl M., Liebhart K. The discursive construction of national identity. Edinburgh : Edinburgh University Press, 2009. 268 p.

4. Кропотухина П. В. Концептуальные метафоры кризисного дискурса Великобритании // Политическая лингвистика. 2017. № 2 (62). С. 94-99.

5. Новикова В. П. Поле битвы Брексит : лингвокогнитивный анализ // Политическая лингвистика. 2019. № 2 (74). С. 93-99.

6. Дьякова Е. Ю. Использование социально-политического феномена BREXIT в создании имиджа британских университетов // Вестник Воронеж. гос. ун-та. Cер.: Лингвистика и межкультурная коммуникация. 2019. № 2. С. 28-33.

7. Алиева T. В. Референдум Брексит : языковые средства актуализации оппозиции «свой-чужой» // Вестник Моск. гос. обл. ун-та. Сер.: Лингвистика. 2017. № 3. C. 8-13.

8. Baker P., Ellece S. Key Terms in Discourse Analysis. London ; NY : Continuum, 2011. 240 p.

9. Cillia R. de, Reisigl M., Wodak R. The discursive construction of national identities // Discourse and Society. 1999. No. 12:2. Pp. 149-173.

10. Benwell B., Stokoe E. Discourse and identity. Edinburgh : Edinburgh University Press, 2006. 328 p.

11. Гаджиев K. С. Национальная идентичность : концептуальный аспект // Вопросы философии. 2011. № 10. С. 3-16.

12. Woodward K. Identity and Difference. London : Sage, 1997. 358 p.

13. Lynch $K$. What Time is this Place? Cambridge : MIT Press, 1972. 277 p.

14. Кожемякин Е. А. Дискурсивное конструирование национальной идентичности в новогодних телевизионных обращениях президента к гражданам России // Дискурсология : возможности интерпретации гуманитарного знания : тез. докл. участников Всерос. на- уч.-практ. конф. с междунар. участием / отв. ред. Л. Н. Синельникова. Ялта, 2018. С. 29-30.

15. Солопова О.А. Метафорическое моделирование образов прошлого, настоящего и будущего в дискурсе парламентских выборов в России (2003 год) и Великобритании (2001 год) : дис. ... канд. филол. наук. Екатеринбург, 2006. 245 с.

16. Reisigl M., Wodak R. The discourse-historical approach // Wodak R., Meyer M. (eds.) Methods of Critical Discourse Analysis. London : SAGE, 2009. Pp. 87-121.

17. Sowińska A., Dubrovskaya T. Discursive construction and transformation of 'us' and 'them' categories in the newspaper coverage on the US anti-ballistic missile system: Polish versus Russian view // Discourse \& Communication. 2012. No. 6 (4). Pp. 449-468.

18. Dictionary.com. URL: https://www.dictionary. com/browse/rise-from-the-ashes.html

19. Кузьменкова Ю. Б. От традиций культуры к нормам речевого поведения британцев, американцев и россиян. М. : МАКС Пресс, 2008. 316 с.

20. Ратохина А. С., Ленеи А. В. Лингвистическая репрезентация стратегии дистанцирования в коммуникативном поведении парламентариев Великобритании // Филологические науки. Вопросы теории и практики. 2017. № 12 (78) : в 4 ч. Ч. 2. С. 138-141.

\section{ИСТОЧНИКИ}

1. Benn 13.06.2016 - Shadow Foreign Secretary Hilary Benn on Monday gave a speech campaigning against "Brexit." June 13, 2016. URL: https://www.newsweek.com/ brexit-hilary-benn-speech-full-text-469547.html

2. Cameron 09.05.2016 - PM speech on the UK's strength and security in the EU, May 9, 2016. URL: https:// www.gov.uk/government/speeches/pm-speech-on-the-uksstrength-and-security-in-the-eu-9-may-2016.html

3. Farage 20.09.2013 - Nigel Farage's speech at the UKIP conference, September 20, 2013. URL: https://blogs. spectator.co.uk/2013/09/nigel-farages-speech-full-text-andaudio/.html

4. Johnson 09.05.2016 - Boris Johnson's speech on the EU referendum. The liberal cosmopolitan case to Vote Leave, May 9, 2016. URL: http://www.voteleavetakecontrol. org/boris_johnson_the_liberal_cosmopolitan_case_to_ vote_leave.html

5. Johnson 14.02.2018 - Full text: Boris Johnson's Brexit speech, February 14, 2018. URL: https:/www.gov. uk/government/speeches/foreign-secretary-speech-unitingfor-a-great-brexit.html

6. May 22.09.2017 - PM's Florence speech: a new era of cooperation and partnership between the UK and the EU, September 22, 2017. URL: https://www.gov.uk/government/ speeches/pms-florence-speech-a-new-era-of-cooperationand-partnership-between-the-uk-and-the-eu.html

7. Mogg 10.06.2016 - Jacob Rees-Mogg MP Speaks on Brexit, June 10, 2016. URL: https://www.youtube.com/ watch?v=Mk6Ymy75814.html 


\section{REFERENCES}

1. Dubrovskaya T. V. 'I Was the First Westerner, The Only English Person: diskursivnoe konstruirovanie natsional'noj identichnosti In Vestnik Rossijskogo universiteta druzhby narodov. Seriya Lingvistika. 2015. № 2. Pp. 25-40.

2. Kozhemyakin E. A., Kryukova S. V. Yazykovoe modelirovanie natsional'noj identichnosti v politicheskom mediadiskurse (na materiale novogodnikh teleobrashhenij V. V. Putina k Federal'nomu sobraniyu). In Sovremennyj diskurs-analiz. 2018. № 3-2 (20). Pp. 80-95.

3. Wodak R., Cillia R. de, Reisigl M., Liebhart K. The discursive construction of national identity. Edinburgh : Edinburgh University Press, 2009. 268 p.

4. Kropotukhina P. V. Kontseptual'nye metafory krizisnogo diskursa Velikobritanii. In Politicheskaya lingvistika. 2017. № 2 (62). Pp. 94-99.

5. Novikova V. P. Pole bitvy Breksit: lingvokognitivnyj analiz. In Politicheskaya lingvistika. 2019. № 2 (74). Pp. 93-99.

6. D'yakova E. Y. Ispol'zovanie sotsial'no-politicheskogo fenomena BREXIT v sozdanii imidzha britanskikh universitetov. In Vestnik Voronezhskogo gosudarstvennogo universiteta. Seriya: Lingvistika i mezhkul'turnaya kommunikatsiya. 2019. № 2. Pp. 28-33.

7. Alieva T. V. Referendum Breksit: yazykovye sredstva aktualizatsii oppozitsii «svoj-chuzhoj». In Vestnik Moskovskogo gosudarstvennogo oblastnogo universiteta, Seriya: Lingvistika. 2017. № 3. Pp. 8-3.

8. Baker P., Ellece S. Key Terms in Discourse Analysis. London, NY: Continuum, 2011. 240 p.

9. Cillia R. de, Reisigl M., Wodak R. The discursive construction of national identities. In Discourse and Society. 1999. No. 12:2. Pp. 149-173.

10. Benwell B., Stokoe E. Discourse and identity. Edinburgh: Edinburgh University Press, 2006. 328 p.

11. Gadzhiev K. S. Natsional'naya identichnost': kontseptual'nyj aspect. In Voprosy filosofii. 2011. № 10. Pp. 3-16.

12. Woodward K. Identity and Difference. London: Sage, 1997. 358 p.

13. Lynch K. What Time is this Place? Cambridge: MIT Press, 1972. $277 \mathrm{p}$.

14. Kozhemyakin E. A. Diskursivnoe konstruirovanie natsional'noj identichnosti v novogodnikh televizionnykh obrashheniyakh prezidenta k grazhdanam Rossii. In Diskursologiya: vozmozhnosti interpretatsii gumanitarnogo znaniya. Tezisy dokladov uchastnikov vserossijsk. nauchno-praktich. konferentsii s mezhdunarodnym uchastiem. Otvetstvennyj redaktor L. N. Sinel'nikova. 2018. Pp. 29-30.

15. Solopova O. A. Metaforicheskoe modelirovanie obrazov proshlogo, nastoyashhego i budushhego v diskurse

Пензенский государственный университет

Дубровская Т. В., доктор филологических наук, доиент, заведующая кафедрой английского языка

E-mail: gynergy74@gmail.com parlamentskikh vyborov v Rossii (2003 god) $i$ Velikobritanii (2001 god). diss. ... kand. filol. nauk. Ekaterinburg: UrGPU, 2006. 245 p.

16. Reisigl M., Wodak R. The discourse-historical approach // Wodak R., Meyer M. (eds) Methods of Critical Discourse Analysis. London: SAGE, 2009. Pp. 87-121.

17. Sowińska A., Dubrovskaya T. Discursive construction and transformation of 'us' and 'them' categories in the newspaper coverage on the US anti-ballistic missile system: Polish versus Russian view. In Discourse \& Communication. 2012. No. 6 (4). Pp. 449-468.

18. Dictionary.com. Available at: https://www.dictionary.com/browse/rise-from-the-ashes.html

19. Kuz'menkova Y. B. Ot traditsij kul'tury $k$ normam rechevogo povedeniya britantsev, amerikantsev i rossiyan. Moscow: MAKS Press, 2008. 316 p.

20. Ratokhina A. S., Lenets A. V. Lingvisticheskaya reprezentatsiya strategii distantsirovaniya v kommunikativnom povedenii parlamentariev Velikobritanii. In Filologicheskie nauki. Voprosy teorii i praktiki. 2017. № 12(78): v 4 ch. CH. 2. S. 138-141.

\section{SOURCES}

1. Benn 13.06.2016 - Shadow Foreign Secretary Hilary Benn on Monday gave a speech campaigning against "Brexit." June 13, 2016. Available at: https://www.newsweek.com/brexit-hilary-benn-speech-full-text-469547.html

2. Cameron 09.05.2016 - PM speech on the UK's strength and security in the EU, May 9, 2016. Available at: https:/www.gov.uk/government/speeches/pm-speech-onthe-uks-strength-and-security-in-the-eu-9-may-2016.html

3. Farage 20.09.2013 - Nigel Farage's speech at the UKIP conference, September 20, 2013. Available at: https:// blogs.spectator.co.uk/2013/09/nigel-farages-speech-fulltext-and-audio/.html

4. Johnson 09.05.2016 - Boris Johnson's speech on the EU referendum. The liberal cosmopolitan case to Vote Leave, May 9, 2016. Available at: http://www.voteleavetakecontrol.org/boris_johnson_the_liberal_cosmopolitan case to vote leave.html

5. Johnson 14.02.2018 - Full text: Boris Johnson's Brexit speech, February 14, 2018. Available at: https://www. gov.uk/government/speeches/foreign-secretary-speech-uniting-for-a-great-brexit.html

6. May 22.09.2017 - PM's Florence speech: a new era of cooperation and partnership between the UK and the EU, September 22, 2017. Available at: https://www.gov.uk/ government/speeches/pms-florence-speech-a-new-era-ofcooperation-and-partnership-between-the-uk-and-the-eu. html

7. Mogg 10.06.2016 - Jacob Rees-Mogg MP Speaks on Brexit, June 10, 2016. Available at: https://www.youtube. $\mathrm{com} /$ watch?v=Mk6Ymy75814.html

Penza State University

Dubrovskaya T. V., Doctor of Philology, Associate Professor, Head of the English Language Department E-mail: gynergy74@gmail.com 
Прагмалингвистические средства конструирования...

Юськаева Э. И., магистрант кафедры иностранных языков и методики преподавания иностранных языков

E-mail: elmira.yuskaeva@yandex.ru

Поступила в редакиию 13 октября 2019 г.

Принята к публикачии 27 декабря 2019 г.

\section{Для иитирования:}

Дубровская Т. В., Юськаева Э. И. Прагмалингвистические средства конструирования коллективного прошлого в британском политическом выступлении // Вестник Воронежского государственного университета. Серия: Лингвистика и межкультурная коммуникация. 2020. № 1. C. 94-102. DOI: https://doi.org/10.17308/ lic. $2020.1 / 2737$
Yuskaeva E. I., Post-graduate Student of the Foreign Languages and Methods of Teaching Foreign Languages Department

E-mail:elmira.yuskaeva@yandex.ru

Received: 13 October 2019

Accepted: 27 December 2019

\section{For citation:}

Dubrovskaya T. V., Yuskaeva E. I. Pragmalinguistic means of constructing the common past in british political speech. Proceedings of Voronezh State University. Series: Linguistics and Intercultural Communication. 2020. No. 1. Pp. 94-102. DOI: https://doi.org/10.17308/lic.2020.1/2737 